\title{
Effect of a hydrogymnastics program on the serum levels of high-sensitivity C-reactive protein amongst elderly women
}

\author{
Javier Arturo Hall-López $z^{1,2}$, Paulina Yesica Ochoa-Martínez ${ }^{1,2^{*}}$, Edgar Ismael Alarcón-Meza ${ }^{1,2}$, \\ Fernando Israel Anaya-Jaramillo ${ }^{1}$, Ana María Miranda Botelho Teixeira ${ }^{5}$, \\ José Moncada-Jiménez ${ }^{4}$, José Carlos Ferreira-Reis ${ }^{2,3}$, \\ Estélio Henrique Martin Dantas ${ }^{2,3}$

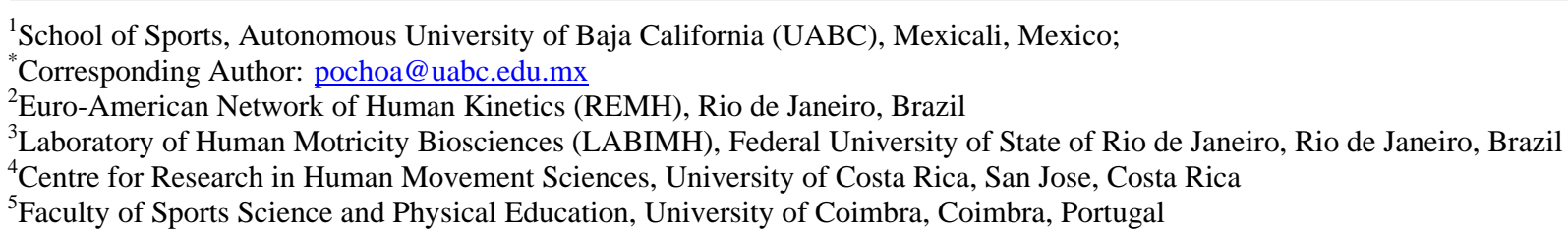

Received 29 November 2013; revised 27 December 2013; accepted 8 January 2014

Copyright (C) 2014 Javier Arturo Hall-López et al. This is an open access article distributed under the Creative Commons Attribution License, which permits unrestricted use, distribution, and reproduction in any medium, provided the original work is properly cited. In accordance of the Creative Commons Attribution License all Copyrights (c) 2014 are reserved for SCIRP and the owner of the intellectual property Javier Arturo Hall-López et al. All Copyright (c) 2014 are guarded by law and by SCIRP as a guardian.

\section{ABSTRACT}

The aim of this study was to evaluate the effect of a hydrogymnastics training program on highsensitivity C-reactive protein in elderly women. The subjects were randomly divided into the experimental group who participates in the hydrogymnastics training program and the control group who was not involved in the training and remained sedentary. The serum levels of highsensitivity C-reactive protein were determined by immunoturbidimetry using $C$-reactive protein (CRP), the training protocol consisted of hydrogymnastics sessions 5 times per week during 12 weeks of intervention, executed in a pool of 1.3 meters divided into three phases: a 10-minute warm-up, 30 minutes of aerobic exercise at $\mathbf{5 0 \%}$ - $60 \%$ of maximum heart rate (monitored by heart rate monitor) and a 10-minute cool down. As a statistical method to compare the results between groups of variables pre and post training, the analysis of variance (ANOVA) mixed $2 \times 2$ (group $\times$ measurement) test was done using SPSS version 17. The founds showed significant changes in the level of high-sensitivity C-reactive protein, and a greater percentage decrease of hs-CRP $(\Delta \%=-37 \%, p=0.001)$ in the experimental group in relation to the control group.
Therefore, it can be inferred that a hydrogymnastics program is effective in reducing the metabolic rate of high-sensitivity C-reactive protein amongst elderly women.

\section{KEYWORDS}

Elderly; hs-CRP; Hydrogymnastics

\section{INTRODUCTION}

Aging is defined as the natural sequence of processes that occurs from birth until death and is characterized by the progressive decline of the body's physiological capabilities, as it also happens over all systems and organs [1]. Elderly adults, first being aimed, after the age of 60, appear the highest rates of morbidity, mortality and the need for medical care and find themselves vulnerable to illnesses common to elderly ages [2], and diseases which affect the person's social development and health, thereby effectively decreasing their quality of life [3].

One disorder that is associated with elderly adults is metabolic syndrome [4], that is a complex disease with various major clinical components of high cardiovascular risk such as: abdominal obesity, insulin resistance with or without glucose intolerance, atherogenic dyslipidemia and hypertension; indistinct and potentially dangerous combinations that substantially elevate the risk of devel- 
oping cardiovascular diseases that require medical treatment and lengthy hospitalizations [5]. In Mexico, the prevalence of metabolic syndrome among adults above 20 years of age, according to the NCEP ATP-III (National Cholesterol Educational Program Adult Treatment Panel-III), is $36.8 \%$. In the case of elderly adults, the National Survey of Health and Nutrition (ENSANUT 2006) showed the prevalence of the indicators of metabolic syndrome to be: obesity $29.7 \%$, abdominal obesity $80.9 \%$, hypertension $25.0 \%$ and diabetes mellitus $20.0 \%$ [6].

Scientific evidence exists that suggests a direct correlation between metabolic syndrome and high-sensitivity C-reactive protein, primarily due to the fact that the latter is a metabolic indicator that plays an important role in the inflammatory processes of endothelial tissue, insulin sensitivity, cirrhosis of the liver, fibrinolysis and endothelial dysfunction as well as being associated with the development of atherosclerosis and cardiovascular risk [7].

High-sensitivity C-reactive protein is found in places where the inflammatory process takes place such as areas around vascular endothelium where atherogenesis is present. It can be synthesized by macrophages, interleukins and by the tumor necrosis factor present in the inflammation process [8] a useful method of diagnosis serving as a marker of inflammation in the prediction of cardiovascular risk [9].

Adults above the age of 60 present higher rates of morbidity and mortality due to cardiovascular and metabolic diseases, as well as a greater need for medical attention than the rest of the population [10]. This causes a negative impact on their quality of life by affecting their physical and psychological health, independence, social relations and their capacity to interact with their surroundings [11].

Aging among elderly adults causes a natural and progressive decrease of their physical capabilities and a loss of control in their movement, caused by a natural loss of skeletal muscle mass [12]. This comes with consequences such as precarious and unbalanced mobility. This in turn, makes elderly adults more fragile and vulnerable, having a diminished functional autonomy for physical activity which has a negative impact on their quality of life $[2,13,14]$. Due to the fact that those deficiencies increase gradually over time, the risk of experiencing functional deterioration directly associated to the presence of some sort of physical disability affects $56 \%$ of men and $62 \%$ of women above the age of 60 [15]. Studies made on elderly adults associate environmental factors with health standards of elderly adults, directly relating the systematic realization of exercise with or without cardiovascular diseases [16]. Likewise, additional investigations had associated it with inversely proportionate levels of high-sensitivity C-reactive protein and markers of metabolic syndrome [17].
Evidence from experimental studies made on elderly adults had showed that multiple benefits are obtained in the practice of physical exercise, among which are low levels of high-sensitivity C-reactive protein [18,19], and a better quality of life [20]. Aging among the world's population would imply that public health services worldwide need to adapt efficiently in order to prevent, diagnose and treat cardiovascular and metabolic diseases [21]. Due to this fact that higher rates of morbidity and need for health services are more commonly observed in this age group than in any other previous stages of life [22], it is important to plan and prescribe adequate exercise for the needs of elderly adults and to minimize their health problems. This in turn will provide them an adequate level of physical performance. The latter is crucial in order to maintain good overall health [18]. The present study proposes some answers to fulfill remained questions: Can a hydrogymnastics exercise program lower high-sensitivity C-reactive protein serum levels in elderly women?

This study considered the hydrogymnastics as an exercise than carried out through realizing rhythmic-gymnastic activities in an aquatic environment. The latter simultaneously counteracts gravity and increases physical capabilities [23]. This type of exercise is especially recommended among people who have limitations with exercise on dry land [24] which in the last ten years has taken popularity and preference among elderly adults by taking advantage of the properties of water in order to provide fluidity and a wider range in movements while diminishing the risk of injuries due to the impact $[23,24]$.

In the study, it has identified the hydrogymnastics as the independent variable and serum levels of high-sensitivity C-reactive protein as the dependent variable, with the objective being to evaluate the effect of a hydrogymnastics exercise program on the serum levels of highsensitivity C-reactive protein in elderly women. There were two established hypotheses (scientific and statistical); our scientific hypothesis anticipates that after adult women joined hydrogymnastics program, noticeable improvement will occur in their serum levels of high-sensitivity C-reactive protein in relation to sedentary women. We present the statistical hypothesis in null and alternative forms, establishing as the acceptance or relative criteria, the level of $\mathrm{p}<0.05$.

\section{OBJECTIVE}

To evaluate the effect of a hydrogymnastics program on the serum levels of high-sensitivity C-reactive protein in elderly women.

\section{METHODOLOGY}

\subsection{Sample Selection of Participants}

This study is considered to be a quasi-experimental, 
where the independent variable is manipulated to measure its effect on the dependent variable, with the purpose of determining the amount of change caused by the prescribed treatment thereby establishing a cause and effect relation [25].

The sample was composed of elderly adult women defined as women above the age of 60 years of age or more, according to the World Health Organization [22], the elderly women were volunteer participants from the county of Mexicali in Baja California, Mexico.

According to the National Institute of Geography and Statistics (INEGI), in the year 2010 the state of Baja California had an elderly adult to total population percentage of $6.9 \%$, corresponding to 229,914 people, of which $60 \%$ were women and $40 \%$ were men. In the city of Mexicali, Baja California the total population of elderly adults constitutes 64,640 which are considered the universe.

The inclusion criteria were: woman, 60 years of age or above, be a resident of the Mexicali county in Baja California, Mexico; be willing to volunteer as a participant in the study; not to have participated in any sort of systemized exercise program for at least three months prior to this study and to be physically able to join daily activities without the need of medical assistance.

The exclusion criteria for this study were: to possess any sort of acute or chronic complication that would hinder hydrogymnastic exercise, such as heart problems, diabetes mellitus, hypertension or asthma; physical complications that could affect the ability to accomplish exercise such as osteoarthritis, joint injuries or recent bone fractures, psychological and neurological problems, having had a major surgery in the past six months or having any sort of infectious disease that could cause inflammation.

Observing the inclusion and exclusion parameters established for this intervention program, an $n$ sample of 25 elderly women was calculated. At the beginning of this investigation 31 subjects were divided randomly through a simple raffle into a control and an experimental group but due to various health and personal reasons there were losses in both groups throughout the length of the investigation. At the end of the investigation 26 elderly women were counted, the losses coming mostly from the control group, an amount which was considered adequate for the size of the sample groups. The control group was composed of 10 elderly women who did not participate in a hydrogymnastics program; this group maintained their normal everyday activities without realizing any sort of systematic physical activity during 12 weeks while the experimental group, composed of 16 elderly women, performed hydrogymnastic exercise.

The present study followed the rules of the General Code of Law in Health Related Investigations in Mexico
[26] and the ethical principles regarding human experimentation proposed by the Helsinki declaration [27]. The facility that was used to carry out this investigation, evaluating and applying the pilot program on the control (CG) and experimental group (EG), was the Aquatic Complex of the School of Sports of the Autonomous University of Baja California in Mexico.

All the participants signed a letter of consent in order to participate in the investigation, which explained the objective of the investigation, its evaluation protocols, possible risks, benefits, consequences, emergency procedures and consensus of participation as a volunteer. The investigation was submitted for evaluation by the ethics committee which is involved in studies on human beings, through the research program of the School of Sports of the Autonomous University of Baja California. Protocol n. 004/2011.

\subsection{General Procedure}

In order to characterize the sample an anamnesis was performed; data was collected regarding age, gender, health and physical activity background. Anthropometric measurements for body mass and height were also obtained using a digital balance scale with a built-in stadiometer, Tanita (USA), following the standards of the International Society for the Advancement of Kinanthropometry (ISAK). The evaluation of the dependent variable, high-sensitivity C-reactive protein, was performed using the following Procedures: blood samples were collected in the morning from 7:00 a.m. to 8:30 a.m. after 12 hours of fasting and 48 hours of rest from physical activity, 5 millimeters of venous blood were collected by a certified biochemist and were placed in EDTA tubes. The quantifications of high-sensitivity C-reactive protein were determined by immunoturbidimetry utilizing the reactive C-reactive protein (CRP)—Randox Laboratories with ranges of $0-10 \mathrm{mg} / \mathrm{L}^{-1}$ and a sensitivity of 0.12 $\mathrm{mg} / \mathrm{L}^{-1}$.

\subsection{Intervention Protocol}

The subjects of this study were put through a hydrogymnastics program of moderate aerobic intensity in accordance with the standards established by the American College of Sports Medicine [18] and the American Heart Association [28]. The program consisted of 60 hydrogymnastics sessions with an exercise frequency of 5 times a week. The volume was set to 50 minutes per session, this being divided into 10 minutes of warm-up, 30 minutes of workload with progressively incremental intensities of $50 \%$ of maximum heart rate frequency for the first 6 weeks and $60 \%$ for the final 6 weeks of the program, using the formula Max HR $=208-0.7 \times$ age [29], exercising through alternating movements between arms 
and legs, monitored using a heart rate monitor Polar FT7® (Finland) followed by 10 minutes of relaxation.

The statistical procedures proposed for an adequate analysis of this investigation were to characterize the sample and evaluate the hypothesis in the following manner:

Using descriptive statistical techniques the investigated universal sample was characterized and a description of the evaluated data was produced. Utilizing methods of localization and dispersion in the standard deviation was then calculated and used to verify the sample symmetry [25]. The acquired statistical results were processed into charts and graphs using SPSS 17 software. Test de Shapiro-Wilk was use in order to determine the normality of the groups and the homogeneity of the sample.

With the goal of establishing all the possibilities of comparison inter and intra group mixed $2 \times 2$ (groups $\times$ measurements) (ANOVA) variance analysis tests were performed for the variable of serum levels of high-sensitivity C-reactive protein with the purpose of maintaining the scientific validity of the investigation. The significance level of $p<0.05$, 95\% probability of accuracy of the results or negative event with a probability of $5 \%$ per case. Percentage changes $(\Delta \%)$ were also calculated for each study group [ (Media post - Media pre)/Media pre] $\times$ 100 [30].

\section{RESULTS}

The participating subjects in the present study were 26 elderly women divided randomly into one experimental group (EG, $n=16$, age of $67.5 \pm 5.4$ years old) that partook in the hydrogymnastics exercise program and one control group (CG, $n=10$, age of $67.4 \pm 4.7$ years old) who did not take part of the exercise program, the general characteristics of the sample can be observed in Table 1.

For the variable of serum levels of high-sensitivity C-reactive protein, mixed $2 \times 2$ (group $\times$ measurements) (ANOVA) variance analysis tests were realized, establishing the level of significance a priori to $\alpha \leq 0.05$. The results of the ANOVA $2 \times 2$ tests showed repeated statistically significant measurements $(p=0.001)$ between the groups and the measurements of the dependent variable in the experimental group, there were no statistically significant changes found in the control group $(p=0.832)$ (Figure 1).

The percentage changes $(\Delta \%)$ for each study group were calculated [(Mediapost - Mediapre)/Mediapre] $\times$ 100. The evidence showed a percentage change in the experimental group $(n=16)$ of $-37\left(\mathrm{mg} / \mathrm{L}^{-1}\right)$ on the serum levels of high-sensitivity C-reactive protein in comparison with that of $-0.7\left(\mathrm{mg} / \mathrm{L}^{-1}\right)$ from the control group $(\mathrm{n}=10)$ (Figuer 2).

\section{DISCUSSION AND CONCLUSIONS}

The results presented in this study cover the length of 60 hydrogymnastic training sessions, with a frequency of 5

Table 1. Descriptive statistics $(M \pm D E)$ of the volunteer women in the study $(n=26)$.

\begin{tabular}{|c|c|c|c|c|}
\hline \multirow{2}{*}{ Variables } & \multicolumn{2}{|c|}{ Experimental $(\mathrm{n}=16)$} & \multicolumn{2}{|c|}{ Control $(n=10)$} \\
\hline & Pre & Post & Pre & Post \\
\hline \multicolumn{5}{|l|}{ Anthropometric } \\
\hline Weight (Kg) & $74.09 \pm 10.74$ & $73.27 \pm 10.81$ & $76.26 \pm 15.17$ & $76.29 \pm 15.70$ \\
\hline Height (cm) & $155.95 \pm 5.78$ & $155.90 \pm 5.72$ & $153.20 \pm 5.86$ & $152.41 \pm 6.19$ \\
\hline BMI $\left(\mathrm{Kg} / \mathrm{m}^{2}\right)$ & $30.53 \pm .9$ & $30.16 \pm 4.55$ & $32.60 \pm 6.91$ & $32.97 \pm 7.19$ \\
\hline \multicolumn{5}{|l|}{ Dependent } \\
\hline $\mathrm{Hs}-\mathrm{CRP}\left(\mathrm{mg} / \mathrm{L}^{-1}\right)$ & $4.33 \pm 0.78$ & $2.94 \pm 0.52$ & $4.25 \pm 0.99$ & $4.22 \pm 1.18$ \\
\hline
\end{tabular}

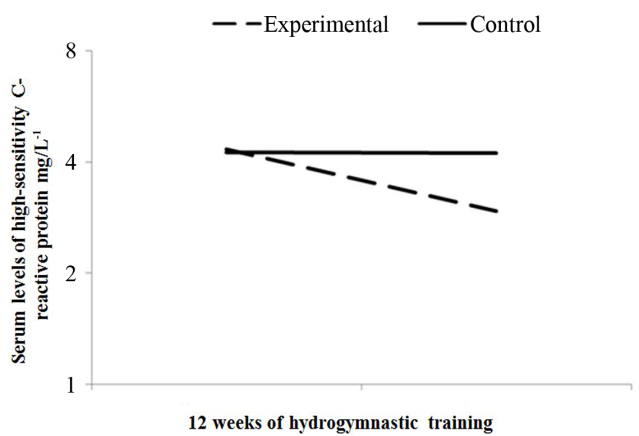

Note: Serum levels of high-sensitivity C-reactive protein in the evaluated subjects of the experimental group (16) and the control group (10) showed significant differences after 12 weeks of hydrogymnastic training $(\mathrm{p} \leq 0.001)$.

Figure 1. Changes in the serum levels of high-sensitivity C-reactive protein $\mathrm{mg} / \mathrm{L}^{-1}$ among the participants of the study $(\mathrm{n}=26)$.

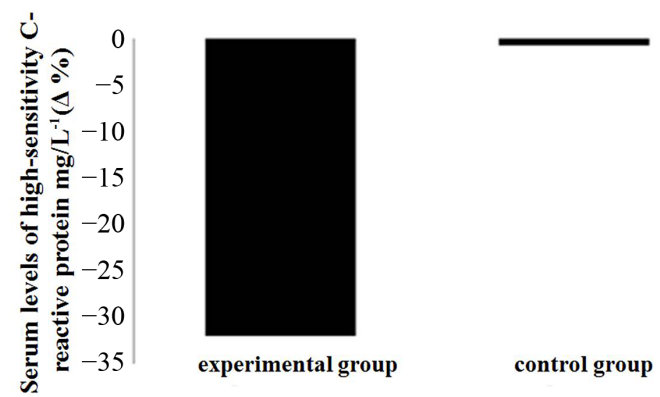

Note: Percentage changes $(\Delta \%)$ of high-sensitivity C-reactive protein from the experimental group (16) and control group (10) before and after 12 weeks of hydrogymnastics training.

Figure 2. Percentage changes $(\Delta \%)$ on the serum levels of high-sensitivity $\mathrm{C}$-reactive protein $\mathrm{mg} / \mathrm{L}^{-1}$ among the participants of the study $(n=26)$. 
sessions per week, for 3 months, where the serum levels of high-sensitivity C-reactive protein were statistically significant results. These results were similar and congruent with studies carried out previously on elderly adults, where an exercise program consisting of walking and strength training was found as a result, with significant changes on the serum levels of high-sensitivity C-reactive protein after training 3 times a week for 8 months [19]. In the present study aerobic training was emphasized and the recommendations for prescribing exercise for elderly adults were set by the American College of Sports Medicine [18] and the American Heart Association [28]; these recommendations were followed by: establishing the duration of the exercise program to 3 months and adapting the volume of training to 5 times per week with progressive overload beginning at $50 \%$ of maximum heart rate frequency (MHR) for the first 6 weeks and 60\% for the last 6 weeks.

A systematic program of controlled dieting and exercise would greatly enhance the results obtained when evaluating serum levels of high-sensitivity C-reactive protein [7]. However, in the current study environmental co-variables that could have effectively altered the results obtained, such as lifestyle, diet and overall physical activities were not monitored or controlled.

In academic literature today there are few studies that show the effects of exercise on high-sensitivity C-reactive protein in elderly adults. Based on the established hypothesis, it is conclusive that 3 months of hydrogymnastics training are effective in reducing the metabolic marker of high-sensitivity C-reactive protein in elderly adult women. However, further studies must be performed in order to corroborate the results obtained on this variable from a hydrogymnastics program. Methodological designs of subsequent studies must present changes such as: a longer hydrogymnastics training program, evaluation of the effects of post-training rest on the variable, application on both genders and on different age groups, and a larger " $n$ " sample that in return will provide more validity to the inferential statistic when analyzing the results of the experiment while consequently providing the possibility to extrapolate the results to subjects with similar characteristics. The express purpose of these studies would be to obtain results that could serve as a reference for planning, execution and evaluation of future interventions directed at preventing, minimizing and/or eliminating the predisposition of elderly adults to suffer from metabolic and cardiovascular diseases. This in turn, will help researchers and professionals who work with this segment of the population to better understand more factors in order to provide better attention.

\section{REFERENCES}

[1] Fulop, T., Larbi, A., Witkowski, J.M., McElhaney, J., Loeb,
M., Mitnitski, A. and Pawelec, G. (2010) Aging, frailty and age-related diseases. [Research Support, Non-U.S. Gov't Review]. Biogerontology, 11, 547-563. http://dx.doi.org/10.1007/s10522-010-9287-2

[2] Barrantes-Monge, M., Garcia-Mayo, E.J., Gutierrez-Robledo, L.M. and Miguel-Jaimes, A. (2007) [Functional dependence and chronic disease in older Mexicans]. [Comparative Study]. Salud Pública de México, 49, S459-S466.

http://dx.doi.org/10.1590/S0036-36342007001000004

[3] Silva, L.M., Silva, A.O., Tura, L.F., Moreira, M.A., Rodrigues, R.A. and Marques Mdo, C. (2012). [Social representations of elders' quality of life]. Revista Gaúcha de Enfermagem, 33, 109-115.

[4] Bener, A., Mohammad, A.G., Ismail, A.N., Zirie, M., Abdullatef, W.K. and Al-Hamaq, A.O. (2010) Gender and age-related differences in patients with the metabolic syndrome in a highly endogamous population. [Research Support, Non-U.S. Gov't]. Bosnian Journal of Basic Medical Sciences, 10, 210-217.

[5] Saely, C.H., Rein, P. and Drexel, H. (2007) The metabolic syndrome and risk of cardiovascular disease and diabetes: Experiences with the new diagnostic criteria from the International Diabetes Federation. [Evaluation Studies Review]. Hormone and Metabolic Research, 39, 642-650. http://dx.doi.org/10.1055/s-2007-985822

[6] Shamah-Levy, T., Cuevas-Nasu, L., Mundo-Rosas, V., Morales-Ruan, C., Cervantes-Turrubiates, L. and Villalpando-Hernandez, S. (2008) [Health and nutrition status of older adults in Mexico: Results of a national probabilistic survey]. Salud Pública de México, 50, 383-389. http://dx.doi.org/10.1590/S0036-36342008000500011

[7] Mora, S., Musunuru, K. and Blumenthal, R.S. (2009) The clinical utility of high-sensitivity C-reactive protein in cardiovascular disease and the potential implication of JUPITER on current practice guidelines. [Research Support, Non-U.S. Gov’t Review]. Clinical Chemistry, 55, 219-228.

http://dx.doi.org/10.1373/clinchem.2008.109728

[8] Rifai, N. (2005) High-sensitivity C-reactive protein: A useful marker for cardiovascular disease risk prediction and the metabolic syndrome. [Comment]. Clinical Chemistry, 51, 504-505. http://dx.doi.org/10.1373/clinchem.2004.044990

[9] Abraham, J., Campbell, C.Y., Cheema, A., Gluckman, T.J., Blumenthal, R.S. and Danyi, P. (2007) C-reactive protein in cardiovascular risk assessment: A review of the evidence. [Review]. Journal of the Cardiometabolic Syndrome, 2, 119-123.

http://dx.doi.org/10.1111/j.1559-4564.2007.05950.x

[10] Veronica, G. and Esther, R.R. (2012) Aging, metabolic syndrome and the heart. Aging and Disease, 3, 269-279.

[11] Figueira, H.A., Giani, T.S., Beresford, H., Ferreira, M.A., Mello, D., Figueira, A.A., Figueira, J.A. and Dantas, E.H. (2009) Quality of life (QOL) axiological profile of the elderly population served by the Family Health Program (FHP) in Brazil. Archives of Gerontology and Geriatrics, 49, 368-372.

http://dx.doi.org/10.1016/j.archger.2008.11.017 
[12] Rolland, Y., Lauwers-Cances, V., Cristini, C., Abellan van Kan, G., Janssen, I., Morley, J.E. and Vellas, B. (2009) Difficulties with physical function associated with obesity, sarcopenia, and sarcopenic-obesity in community-dwelling elderly women: The EPIDOS (EPIDemiologie de l'OSteoporose) Study. [Research Support, Non-U.S. Gov't]. American Journal of Clinical Nutrition, 89, 1895-1900. http://dx.doi.org/10.3945/ajcn.2008.26950

[13] Jang, Y.C. and Van Remmen, H. (2011) Age-associated alterations of the neuromuscular junction. [Research Support, N.I.H., Extramural Research Support, Non-U.S. Gov't Review]. Experimental Gerontology, 46, 193-198. http://dx.doi.org/10.1016/j.exger.2010.08.029

[14] Doubova Dubova, S.V., Perez-Cuevas, R., EspinosaAlarcon, P. and Flores-Hernandez, S. (2010) Social network types and functional dependency in older adults in Mexico. [Research Support, Non-U.S. Gov't]. BMC Public Health, 10, 104. http://dx.doi.org/10.1186/1471-2458-10-104

[15] Avila-Funes, J.A., Gray-Donald, K. and Payette, H. (2006) [Measurement of physical capacities in the elderly: A secondary analysis of the Quebec longitudinal study NuAge]. [Comparative Study Evaluation Studies]. Salud Pública de México, 48, 446-454. http://dx.doi.org/10.1590/S0036-36342006000600002

[16] Lopez-Alegria, F. and De Lorenzi, D.R. (2011) [Lifestyles and quality of life of post menopausal women]. [Research Support, Non-U.S. Gov’t]. Revista Médica de Chile, 139, 618-624. http://dx.doi.org/10.4067/S0034-98872011000500009

[17] Plaisance, E.P. and Grandjean, P.W. (2006) Physical activity and high-sensitivity C-reactive protein. [Review]. Sports Medicine, 36, 443-458. http://dx.doi.org/10.2165/00007256-200636050-00006

[18] American College of Sports Medicine, Chodzko-Zajko, W.J., Proctor, D.N., Fiatarone Singh, M.A., Minson, C.T., Nigg, C.R., Salem, G.J. and Skinner, J.S. (2009) American College of Sports Medicine position stand. Exercise and physical activity for older adults. [Practice Guideline]. Medicine \& Science in Sports \& Exercise, 41, 1510-1530. http://dx.doi.org/10.1249/MSS.0b013e3181a0c95c

[19] Martins, R.A., Neves, A.P., Coelho-Silva, M.J., Verissimo, M.T. and Teixeira, A.M. (2010) The effect of aerobic versus strength-based training on high-sensitivity C-reactive protein in older adults. [Comparative Study Randomized Controlled Trial Research Support, Non-U.S. Gov't]. European Journal of Applied Physiology, 110, 161-169. http://dx.doi.org/10.1007/s00421-010-1488-5

[20] Sato, D., Kaneda, K., Wakabayashi, H. and Nomura, T. (2007) The water exercise improves health-related quality of life of frail elderly people at day service facility. Quality of Life Research, 16, 1577-1585. http://dx.doi.org/10.1007/s11136-007-9269-2
[21] Ham Chande, R. and Gutierrez Robledo, L.M. (2007) [Health and aging in the 20th century]. [Introductory]. Salud Pública de México, 49, S433-S435. http://dx.doi.org/10.1590/S0036-36342007001000001

[22] Gonzalez, C.A. and Ham-Chande, R. (2007) [Functionality and health: A typology of aging in Mexico]. [Comparative Study]. Salud Pública de México, 49, S448-S458. http://dx.doi.org/10.1590/S0036-36342007001000003

[23] Kamioka, H., Tsutani, K., Okuizumi, H., Mutoh, Y., Ohta, M., Handa, S., Okada, S., Kitayuguchi, J., Kamada, M., Shiozawa, N. and Honda, T. (2010) Effectiveness of aquatic exercise and balneotherapy: A summary of systematic reviews based on randomized controlled trials of water immersion therapies. [Research Support, Non-U.S. Gov't Review]. Journal of Epidemiology, 20, 2-12. http://dx.doi.org/10.2188/jea.JE20090030

[24] Kamioka, H., Tsutani, K., Mutoh, Y., Okuizum, H., Ohta, M., Handa, S., Okada, S., Kitayuguchi, J., Kamada, M., Shiozawa, N., Park, S.J., Honda, T. and Moriyama, S. (2011) A systematic review of nonrandomized controlled trials on the curative effects of aquatic exercise. International Journal of General Medicine, 4, 239-260. http://dx.doi.org/10.2147/IJGM.S17384

[25] Thomas, J.R., Nelson, J.K., Silverman, S. and Silverman, S.J. (2001) Research methods in physical activity. 6th Edition, Human Kinetics, Champaign.

[26] Reglamento de la Ley General de Salud en Materia de Investigación para la Salud Census data revisited (2010) From the Diario Oficial de la Federación, México, 1982, Population website.

http://www.salud.gob.mx/unidades/cdi/nom/compi/rlgsmi s.html

[27] Puri, K.S., Suresh, K.R., Gogtay, N.J. and Thatte, U.M. (2009) Declaration of Helsinki, 2008: Implications for stakeholders in research. Journal of Postgraduate Medicine, 55, 131-134.

http://dx.doi.org/10.4103/0022-3859.52846

[28] Nelson, M.E., Rejeski, W.J., Blair, S.N., Duncan, P.W., Judge, J.O., King, A.C., Macera, C.A. and CastanedaSceppa, C., American Heart Association (2007) Physical activity and public health in older adults: Recommendation from the American College of Sports Medicine and the American Heart Association. [Congresses]. Circulation, 116, 1094-1105. http://dx.doi.org/10.1161/CIRCULATIONAHA.107.1856 $\underline{50}$

[29] Tanaka, H., Monahan, K.D. and Seals, D.R. (2001) Agepredicted maximal heart rate revisited. Journal of the American College of Cardiology, 37, 153-156. http://dx.doi.org/10.1016/S0735-1097(00)01054-8

[30] Vincent, W.J. (1999) Statistics in kinesiology. 2nd Edition, Human Kinetics, Champaign. 